\title{
Safety evaluation of a newly-developed dietary fiber: resistant glucan mixture
}

\author{
Hiroyuki Bito, Norihisa Hamaguchi, Hirokazu Hirai and Koichi Ogawa \\ Nihon Shokuhin Kako Co., Ltd., 30 Tajima, Fuji, Shizuoka 417-8530, Japan
}

(Received June 11, 2015; Accepted October 15, 2015)

\begin{abstract}
Resistant glucan mixture (RGM), a water-soluble dietary fiber produced by the random polymerization of glucose with activated carbon as a catalyst at a high temperature, has been recently developed by our group. There has been little physiological and safety research into RGM and therefore we now present our research into its safety. A reverse mutation assay indicated that RGM is not mutagenic either with or without metabolic activation. We conducted a 90-day subchronic oral toxicity study in rats. Male and female rats fed either a $3 \%$ or $5 \% \mathrm{w} / \mathrm{w}$ RGM diet had no muddy or watery stools, and there was no RGM-related death in any group. Although some parameters in the 3\% and 5\% w/w groups were significantly different from those in the control group, these changes were not due to any toxicity from RGM. The results indicated that the No Observed Adverse Effect Level (NOAEL) of RGM was 3.3 and $3.9 \mathrm{~g} / \mathrm{kg}$ body weight (BW) per day in male and female rats, respectively. We then studied the gastrointestinal effects of RGM in healthy adult humans. Gastrointestinal symptoms, such as gurgling sounds, flatus and tenesmus, were mild and transient. In men and women, the maximum no-effect dose for diarrhea was more than $0.9 \mathrm{~g} \mathrm{RGM} / \mathrm{kg} \mathrm{BW}$. The results of our current safety assessment studies suggest that RGM is safe for human consumption.
\end{abstract}

Key words: Resistant glucan mixture, Toxicity, Reverse mutation assay, 90-day subchronic oral toxicity study, Maximum no-effect dose for diarrhea

\section{INTRODUCTION}

Early definitions of dietary fiber include undigested cell storage polysaccharides, as well as undigested cellwall polysaccharides and lignin (Trowell et al., 1976). Subsequent work has revealed that polysaccharides such as chitin and chitosan from animals play a similar physiological role to dietary fiber from plants (Sugano et al., 1978; Kobayashi et al., 1979). Over the last few decades, synthetic carbohydrate polymers, typified by polydextrose and resistant maltodextrin, have been accepted as dietary fiber in many countries and have been widely used in various processed foods and beverages (JECFA, 1981; Shimomura et al., 2005; Okuma et al., 1990; Kametani et al., 2009). Ingestion of these polymers provides numerous physiological benefits such as improvements in serum lipid (Choi et al., 1998; Pronczuk and Hayes, 2006; Kishimoto et al., 2007), carbohydrate metabolism (Jie et al., 2000; Wakabayashi et al., 1999), intestinal flora (Peuranen et al., 2004; Okuma and Matsuda, 2002), and even modulation of immune parameters (Peuranen et al., 2004). Although they are safe and useful, these materials are difficult to produce efficiently. The condensation reaction to produce polydextrose requires citric acid or phosphoric acid as a catalyst. The residual soluble catalyst must then be removed by an ion-exchange process to make the product palatable and to improve its color. Resistant maltodextrin is produced by amylase treatment and fractionation of starch roasted with hydrochloric acid. The yield of resistant maltodextrin is lower than of polydextrose because of the fractionation process.

We have recently developed a simple and efficient procedure to obtain water-soluble dietary fiber, a resistant glucan mixture (RGM). RGM has several unique features: (1) it is obtained by heating glucose syrup with activated carbon as a catalyst; (2) activated carbon can be easily removed by filtration because it is insoluble; (3) RGM is a non-digestible polysaccharide composed only of glucose units; (4) RGM, like polydextrose and resistant maltodextrin, has a lower viscosity compared with other soluble dietary fibers such as pectin, guar gum and glucomannan; and (5) the same structural carbohydrate polymer exists

Correspondence: Hiroyuki Bito (E-mail: hiroyuki.bito@nisshoku.co.jp) 
in heat-processed foods (Hamaguchi et al., 2015). These features indicated that RGM could be used as a dietary fiber and a sugar substitute in various foods.

Indigestible carbohydrates are resistant to digestion and absorption in the small intestine and mostly flow into the large intestine. In the large intestine, they are converted through fermentation by bacteria into short-chain fatty acids (SCFA) such as acetate, propionate and butyrate, lactate and succinate which are used as an energy source by the host (Mascolo et al., 1991). However, an overdose of indigestible carbohydrates can cause transient diarrhea because, along with the fermented products, they increase the osmotic pressure in the intestinal lumen (Hammer et al., 1990). The dietary fiber content of RGM is $81.8 \%$ as measured by enzymatic high-performance liquid chromatography (Hamaguchi et al., 2015). RGM is thought to be poorly hydrolyzed in the small intestine so most of it reaches the large intestine. Thus RGM, as well as other soluble dietary fibers such as polydextrose, resistant maltodextrin, inulin and hydrolyzed natural fiber, acts as an osmotic substance in the large intestine. This may induce gastrointestinal symptoms in humans such as diarrhea, abdominal pain, tenesmus, gurgling sounds, abdominal bloating, flatus, vomiting, and abdominal discomfort and nausea. RGM therefore shares many features with better-known dietary fibers. Crystal malt, caramel coloring and acid saccharification syrup all contain RGM but their RGM content is very low. Its safety for use in food and beverage products has not been adequately assessed. Therefore, in the present study, a reverse mutation assay (Ames test), a 90-day subchronic oral toxicity study in rats, and a test for maximum no-effect dose for diarrhea in humans were conducted to determine the safety of RGM for human consumption.

\section{MATERIALS AND METHODS}

\section{Test substance}

The test substance was RGM in powder form (Fit Fiber ${ }^{\circledR} \# 80$, Nihon Shokuhin Kako Co. Ltd., Tokyo, Japan), a non-viscous, water-soluble dietary fiber derived from glucose. The dietary fiber content of the RGM powder, measured using enzymatic high-performance liquid chromatography method (AOAC (Association of Official Analytical Chemists) 2001.03), was $81.8 \%$ for the 90 -day subchronic repeated oral toxicity study in rats and $82.6 \%$ for the other experiments.

\section{Reverse mutation assay (Ames test)}

The assay was performed according to OECD Guidelines for Testing of Chemicals 471 (OECD, 1997). The bacterial strains tested were Salmonella typhimurium (TA100, TA1535, TA98, and TA1537) and Escherichia coli (WP2 uvrA) obtained from the Division of Genetics and Mutagenesis, National Institute of Health Sciences (Tokyo, Japan). The S9 fraction and cofactor-I were purchased from Kikkoman Co. Ltd. (Chiba, Japan) and the Oriental Yeast Co., Ltd. (Tokyo, Japan), respectively. The S9 mix was prepared just before use for metabolic activation. The doses of RGM powder were 313, 625, $1,250,2,500$ and 5,000 $\mu \mathrm{g} /$ plate. Sterile distilled water was used as the dilution solution and the negative control. 2-(2-Furyl)-3-(5-nitro-2-furyl) acrylamide (AF-2), sodium azide (SAZ), 2-methoxy-6-chloro-9-[3-(2-chloroethyl)aminopropylamino]acridine dihydrochloride (ICR-191), 2-aminoanthracene (2AA) and benzo[a]pyrene (B $[a] \mathrm{P})$ were used as the positive controls. The test solutions, the negative control and positive control $(0.1 \mathrm{~mL}$ of each) were placed in small sterilized test tubes. Then $0.5 \mathrm{~mL}$ of $0.1 \mathrm{~mol} / \mathrm{L}$ sodium phosphate buffer $(\mathrm{pH} 7.4)$ was added for the system without metabolic activation or $0.5 \mathrm{~mL}$ of S9 mix was added for the system with metabolic activation. $0.1 \mathrm{~mL}$ of bacterial suspension was then added to each tube. Finally, $2.0 \mathrm{~mL}$ of top agar was added to each tube, and this mixture was overlaid uniformly on the minimal glucose agar plate medium. The plates were incubated for $48 \mathrm{hr}$ at $37^{\circ} \mathrm{C}$. The experiment was performed in triplicate and repeated twice. Results were deemed to be positive if the number of revertant colonies was at least double the number of natural revertant colonies (i.e. the negative control value) and if reproducibility and dosedependence were observed in the two tests.

\section{0-day subchronic oral toxicity study in rats}

The present study was performed according to "Partial Revision of Guidelines for Repeated-Dose Toxicity Studies" (Notification No. 655 of the Pharmaceutical and Medical Safety Bureau, Ministry of Health and Welfare, Japan, April 5, 1999) and "Guidelines for Repeated-Dose Toxicity Studies" (Notification No.29 of the Environmental Health Bureau, Ministry of Health and Welfare, Japan, March 22, 1996). The 30 male and 30 female Sprague-Dawley rats (Crl:CD(SD) SPF rat, 4-week-old, Charles River Laboratories Japan Inc., Kanagawa, Japan) were acclimatized for 2 weeks and fed a control diet (CR-LPF, Oriental Yeast Co. Ltd.). The rats were subsequently allocated to three groups on the basis of body weight to obtain normalized body weights across the groups. There were 10 males and 10 females per group. The dose was determined by a 14-day preliminary study carried out before the present study. The groups were: control diet, 3\% RGM diet and 5\% RGM diet. The 
Safety assessment of resistant glucan mixture

process for preparing the RGM diet was as follows: the requisite amounts of $\mathrm{RGM}$ and powdered control diet for each dose level were weighed; a concentrated admixture was first prepared by mixing the test substance with a small amount of control diet; and finally the concentrated admixture was mixed with the rest of the control diet to achieve the prescribed concentrations. The RGM diets were prepared every 15 days, because RGM in the diet had been confirmed as stable and uniform from the day of preparation to day 28 . Rats were allowed free access to food and water throughout the experimental period (90 days). The rats were individually observed for symptoms and body weight and food consumption were measured every 3 or 4 days (twice per week). In week 13 (day 86 to 87 ), all animals were put in individual cages with a urine collector then 4-hr urine was collected under conditions of diet deprivation with free access to water. Consequently, 20-hr urine was collected with free access to diet and water. Urine samples were used for urinalysis. Ophthalmological examination was carried out on six animals in each group in week 13 (day 88). Blood samples were taken from the abdominal aorta of all the rats under isoflurane anesthesia with prior food deprivation, after which the rats were euthanized by bleeding to allow necropsy to be performed.

Blood samples were collected for general hematology, hematological analysis (red blood cell count (RBC), mean hemoglobin volume (HGB), hematocrit value (HCT), mean corpuscular volume (MCV), mean corpuscular hemoglobin $(\mathrm{MCH})$, mean corpuscular hemoglobin concentration (MCHC), reticulocyte count (Retic), platelet count (PLT), white blood cell count (WBC), lymphocyte (LYMP), neutrophils (NEUT), eosinophils (EOS), basophils (BASO), monocyte (MONO), large unstained cells (LUC), prothrombin time (PT), activated partial thromboplastin time (APTT) and fibrinogen volume (FIB)) and blood chemical analysis (aspartate aminotransferase (AST), alanine aminotransferase (ALT), lactate dehydrogenase (LDH), alkaline phosphatase (ALP), $\gamma$-glutamyl transpeptidase $(\gamma$-GTP), total cholesterol (T-CHO), triglyceride (TG), phospholipid (PL), total bilirubin (T-BIL), glucose (GLU), blood urea nitrogen (BUN), creatinine (CRE), $\mathrm{Na}, \mathrm{K}, \mathrm{Cl}, \mathrm{Ca}$, inorganic phosphorus $(\mathrm{P})$, total protein $(\mathrm{TP})$, albumin, globulin and albumin: globulin $(\mathrm{A} / \mathrm{G})$ ratio). The blood cells were counted using an automated blood cell counter (Advia 120, Siemens Healthcare Diagnostics Inc., Tokyo, Japan). PT, APTT and FIB were measured using an automated coagulometer (ACL Elite Pro, Instrumentation Laboratory, Bedford, MA, USA). The blood biochemical parameters were measured using a biochemical analyzer
(TBA-120FR, Toshiba Medical Systems Corp., Tochigi, Japan). After exsanguination, the major organs of all the rats were collected and weighed (brain, pituitary, thyroid, adrenal gland, thymus, spleen, heart, lungs, salivary glands, liver, kidneys, testes or ovary, uterus or prostate and seminal vesicles or oviducts). The full set of tissues (cerebrum, cerebellum, spinal cord, sciatic nerve, eye, optic nerve, harderian gland, pituitary, thyroid gland, parathyroid gland, adrenal gland, thymus, spleen, submandibular lymph node, mesenteric lymph node, heart, thoracic aorta, trachea, lung, tongue, esophagus, stomach, duodenum, jejunum, ileum, cecum, colon, rectum, submandibular gland, sublingual gland, liver, pancreas, kidney, urinary bladder, testes, epididymis, prostate, seminal vesicle, ovary, uterus, vagina, oviduct, mammary gland, sternum, femur, femoral skeletal muscle, skin, nasal cavity and zymbal gland) of all rats was fixed and preserved in 10\% neutral-buffered formalin. The eye and optic nerves were fixed with phosphate buffer containing 3\% glutaraldehyde $/ 2.5 \%$ formalin and the testes and epididymides were fixed with Bouin's solution, and then preserved in phosphate-buffered $10 \%$ formalin. All the organs and tissues of both sexes in all groups were sectioned and stained with hematoxylin and eosin. The stained sections from the control group and 5\% RGM group were observed microscopically. If any changes were suspected as being caused by RGM, we also examined sections in the 3\% RGM group microscopically.

\section{Maximum no-effect dose for diarrhea in humans}

The study of RGM ingestion by humans was performed in accordance with the Helsinki Declaration under the approval of the Ethics Committee of the Serabie Shinbashi Clinic. The subjects were 20 adult volunteers (10 men and 10 women) in good health between 20 and 59 years of age. The subjects repeatedly ingested the test substance beginning at the lowest dose $(0.3 \mathrm{~g} / \mathrm{kg} \mathrm{BW})$ then progressed to the higher doses $(0.5,0.7,0.9 \mathrm{~g} / \mathrm{kg}$ BW) with a 1-week washout period between administrations. Doses based on dry matter of RGM powder, depending on the subjects' body weights, were dissolved in $200 \mathrm{~mL}$ of water. The solutions were ingested after two hours from lunch prepared at the test facility. From the day before ingestion to the day after ingestion, the subjects were prohibited from ingesting oligosaccharides, sugar alcohols, yogurt, milk and alcoholic beverages. Additionally, all subjects recorded on a form the incidence of abdominal symptoms (abdominal pain, tenesmus, gurgling sounds, abdominal bloating, flatus, vomiting and discomfort and nausea), defecation frequency, the shape and the hardness of stools and other negative 
H. Bito et al.

side effects within $24 \mathrm{hr}$ of RGM ingestion. They were also asked to record any variation in their physical condition, lifestyle, intake of supplements and drugs and intake of alcohol. The stool shape was subjectively rated on a 6-level scale: (1) very hard (pellet-shaped); (2) hard-solid; (3) normal (banana-shaped); (4) soft, pasty; (5) muddy; and (6) watery. Muddy stools and watery stools were categorized as diarrhea. The maximum no-effect dose was defined as the dose level at which diarrhea did not occur in any subject.

\section{Statistics}

All data obtained in this study were expressed as the mean \pm S.D. In the study of 90-day subchronic oral toxicity in rats, the body weight, food consumption, food efficiency, water intake, quantitative data from urinalysis, hematology, blood chemistry and organ weights were statistically analyzed for differences between the control group and each concentration group. Initially, the data were analyzed for homogeneity of variance using Bartlett's test (level of significance: 1\%, two-tailed). The difference between the control group and each concentration group was analyzed using Dunnett's test if the variance was homogeneous and Steel's test if the variance was heterogeneous (level of significance: $5 \%$ and $1 \%$, two-tailed). All analyses were performed using the integrated statistical package, SAS version 9.1.3 (SAS Institute Inc., Cary, NC, USA).

\section{RESULTS}

\section{Reverse mutation assay (Ames test)}

The results from the reverse mutation assay are shown in Table 1. No precipitation or coloration by the test substance on the test plate was observed with or without metabolic activation. Observation of bacteria using a stereoscopic microscope revealed no growth inhibition in any strains with or without metabolic activation. There was less than a two-fold increase in numbers of revertant colonies compared with the number of spontaneous revertant colonies (the negative control value). There was also no dose-dependence in any test system with or without metabolic activation. Both tests produced similar results and reproducibility was also confirmed. We also observed a greater than two-fold increase in the number of revertant colonies in the positive-control plates of each test strain compared with the negative control. We can thus conclude that RGM had no bacterial reverse mutagenic activity under these conditions.

\section{0-day subchronic oral toxicity study in rats}

One male in the 5\% w/w RGM group died on day 81 . This animal had no clinical abnormalities or any abnormal changes in body weight or food consumption. At necropsy, a mild enlargement of the cecum was observed, with luminal dilatation of the cecum seen histopathologically. The cecal contents were in the form of an almost solid paste, in amounts greater than normal for a rat. However, no other changes were noted.

The body weights of the RGM groups were comparable with those of the control group. Changes in food consumption over the administration period are shown in Fig. 1. Food consumption was significantly lower in the male $3 \% \mathrm{w} / \mathrm{w}$ group on day 77 . Food consumption was significantly higher in the female $5 \% \mathrm{w} / \mathrm{w}$ group on day 63. At all the other time points during the administration period, no significant differences were observed between any groups. The mean intake of RGM during the administration period was 1,954 and $3,318 \mathrm{mg} / \mathrm{kg} \mathrm{BW}$ per day in males, and 2,254 and 3,874 mg/kg BW per day in females in the $3 \%$ and $5 \% \mathrm{w} / \mathrm{w}$ groups, respectively. There were no ophthalmological abnormalities in any of the animals examined.

The results of urinalysis are shown in Table 2. There were significantly low values in the one day's excretion of $\mathrm{Na}, \mathrm{K}$ and $\mathrm{Cl}$ in the male $3 \% \mathrm{w} / \mathrm{w}$ group. In the qualitative and other quantitative items, there were no changes related to the test substances.

The results of hematological and blood chemical analysis are shown in Tables 3 and 4 . A significantly low value in $\mathrm{MCH}$ in the male $5 \% \mathrm{w} / \mathrm{w}$ group and a significantly low value in FIB in the female $5 \% \mathrm{w} / \mathrm{w}$ group were recorded. Significantly low values in ALP activity were recorded in the male $3 \%$ and $5 \% \mathrm{w} / \mathrm{w}$ groups. A significantly low value in AST activity was recorded in the male $3 \% \mathrm{w} / \mathrm{w}$ group. Regarding organ weights relative to body weight, the relative weight of the prostate in the $3 \% \mathrm{w} / \mathrm{w}$ group was significantly higher than the control (Table 5). In the histopathological analysis, there were no changes related to the test substances in any organ or tissue from either sex.

\section{Maximum no-effect dose for diarrhea in humans}

The self-reported characteristics of stools after ingestion of RGM are shown in Table 6. No diarrhea (muddy or watery stools) was observed in any subject at the maximum dose level $(0.9 \mathrm{~g} / \mathrm{kg} \mathrm{BW})$. Therefore, the maximum no-effect dose for diarrhea was estimated to be more than $0.9 \mathrm{~g} / \mathrm{kg} \mathrm{BW}$ for both sexes. No subject experienced any gastrointestinal symptoms at the lower two dose levels (0.3 and $0.5 \mathrm{~g} / \mathrm{kg} \mathrm{BW}$ ); however, a few subjects experi- 
Safety assessment of resistant glucan mixture

Table 1. Effect of resistant glucan mixture on revertant colonies in Ames assay.

\begin{tabular}{|c|c|c|c|c|c|c|c|}
\hline & & Test article dose & & Number o & ints (numbe & nies/plate) & \\
\hline & & ( $\mu \mathrm{g} /$ plate $)$ & & air substitut & & Fra & type \\
\hline & & & TA100 & TA1535 & WP2uvrA & TA98 & TA1537 \\
\hline & & Negative control & $110 \pm 12$ & $13 \pm 2$ & $22 \pm 3$ & $27 \pm 3$ & $9 \pm 4$ \\
\hline & & 313 & $117 \pm 13$ & $12 \pm 3.0$ & $23 \pm 5$ & $20 \pm 5$ & $9 \pm 1$ \\
\hline & $\overrightarrow{0}$ & 625 & $119 \pm 12$ & $13 \pm 8.0$ & $26 \pm 7$ & $31 \pm 5$ & $7 \pm 2$ \\
\hline & 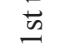 & 1250 & $98 \pm 7$ & $14 \pm 1$ & $25 \pm 5$ & $31 \pm 6$ & $14 \pm 2$ \\
\hline & & 2500 & $106 \pm 6$ & $15 \pm 3$ & $22 \pm 4$ & $22 \pm 6$ & $13 \pm 3$ \\
\hline$\underset{.}{ \pm}$ & & 5000 & $117 \pm 9$ & $11 \pm 2$ & $24 \pm 3$ & $24 \pm 2$ & $7 \pm 1$ \\
\hline$\sum_{\alpha}$ & & Negative control & $89 \pm 12$ & $14 \pm 4$ & $23 \pm 4$ & $25 \pm 5$ & $21 \pm 6$ \\
\hline & & 313 & $90 \pm 12$ & $8 \pm 2$ & $16 \pm 1$ & $23 \pm 7$ & $20 \pm 4$ \\
\hline & 苞 & 625 & $98 \pm 4$ & $11 \pm 1$ & $31 \pm 7$ & $25 \pm 4$ & $28 \pm 1$ \\
\hline & तี & 1250 & $90 \pm 6$ & $11 \pm 3$ & $23 \pm 2$ & $24 \pm 5$ & $21 \pm 6$ \\
\hline & & 2500 & $93 \pm 9$ & $9 \pm 3$ & $18 \pm 3$ & $21 \pm 5$ & $25 \pm 6$ \\
\hline & & 5000 & $92 \pm 9$ & $12 \pm 4$ & $21 \pm 3$ & $23 \pm 6$ & $20 \pm 5$ \\
\hline & & Negative control & $133 \pm 5$ & $11 \pm 3$ & $27 \pm 5$ & $34 \pm 4$ & $9 \pm 3$ \\
\hline & & 313 & $135 \pm 10$ & $7 \pm 1$ & $30 \pm 8$ & $34 \pm 8$ & $9 \pm 3$ \\
\hline & 范 & 625 & $134 \pm 6$ & $10 \pm 2$ & $27 \pm 4$ & $33 \pm 12$ & $12 \pm 4$ \\
\hline & 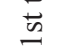 & 1250 & $139 \pm 19$ & $9 \pm 1$ & $30 \pm 3$ & $33 \pm 1$ & $12 \pm 3$ \\
\hline & & 2500 & $126 \pm 3$ & $11 \pm 4$ & $24 \pm 6$ & $33 \pm 4$ & $10 \pm 3$ \\
\hline$\underbrace{ \pm}_{\triangle}$ & & 5000 & $133 \pm 1$ & $13 \pm 4$ & $32 \pm 8$ & $33 \pm 11$ & $11 \pm 1$ \\
\hline$\sum_{2}$ & & Negative control & $133 \pm 11$ & $14 \pm 3$ & $25 \pm 3$ & $40 \pm 3$ & $19 \pm 6$ \\
\hline & & 313 & $127 \pm 9$ & $8 \pm 7$ & $17 \pm 4$ & $35 \pm 4$ & $22 \pm 3$ \\
\hline & $\overrightarrow{\underline{\omega}}$ & 625 & $115 \pm 8$ & $10 \pm 8$ & $26 \pm 8$ & $32 \pm 5$ & $21 \pm 3$ \\
\hline & तี & 1250 & $118 \pm 10$ & $10 \pm 2$ & $18 \pm 5$ & $31 \pm 3$ & $22 \pm 3$ \\
\hline & & 2500 & $116 \pm 13$ & $10 \pm 3$ & $24 \pm 6$ & $38 \pm 10$ & $22 \pm 6$ \\
\hline & & 5000 & $135 \pm 19$ & $11 \pm 3$ & $23 \pm 3$ & $36 \pm 6$ & $22 \pm 5$ \\
\hline & & Name & AF-2 & SAZ & $\mathrm{AF}-2$ & $\mathrm{AF}-2$ & ICR-191 \\
\hline$\underset{\Xi}{.}$ & & Dose ( $\mu \mathrm{g} /$ plate $)$ & 0.01 & 0.5 & 0.01 & 0.1 & 1 \\
\hline$\sum$ & $1 \mathrm{st}$ & Positive control & $507 \pm 8$ & $276 \pm 13$ & $70 \pm 6$ & $481 \pm 24$ & $1297 \pm 275$ \\
\hline & $\overline{2 n d}$ & & $663 \pm 44$ & $288 \pm 30$ & $81 \pm 2$ & $485 \pm 37$ & $1385 \pm 200$ \\
\hline & & Name & $\mathrm{B}[a] \mathrm{P}$ & $2 \mathrm{AA}$ & $2 \mathrm{AA}$ & $\mathrm{B}[a] \mathrm{P}$ & $\mathrm{B}[a] \mathrm{P}$ \\
\hline$\underbrace{ \pm}_{x}$ & & Dose ( $\mu \mathrm{g} /$ plate $)$ & 5 & 2 & 10 & 5 & 5 \\
\hline$\sum_{a}$ & $1 \mathrm{st}$ & Positive control & $896 \pm 26$ & $252 \pm 18$ & $716 \pm 51$ & $360 \pm 45$ & $102 \pm 17$ \\
\hline & 2 nd & & $994 \pm 51$ & $276 \pm 26$ & $892 \pm 4$ & $362 \pm 15$ & $102 \pm 22$ \\
\hline
\end{tabular}

Values are means \pm S.D. Strains; TA100: Salmonella typhimurium TA100, TA1535: Salmonella typhimurium TA1535, WP2uvrA: Escherichia coli WP2 uvrA, TA98: Salmonella typhimurium TA98, TA1537: Salmonella typhimurium TA1537. Positive control; AF-2: 2-(2-Furyl)-3-(5-nitro-2-furyl) acrylamide, SAZ: sodium azide, ICR-191: 2-methoxy-6-chloro-9-[3-(2-chloroethyl)aminopropylamino]acridine dihydrochloride, 2AA: 2-aminoanthracene, $\mathrm{B}[a] \mathrm{P}:$ benzo $[a]$ pyrene. 


\section{H. Bito et al.}
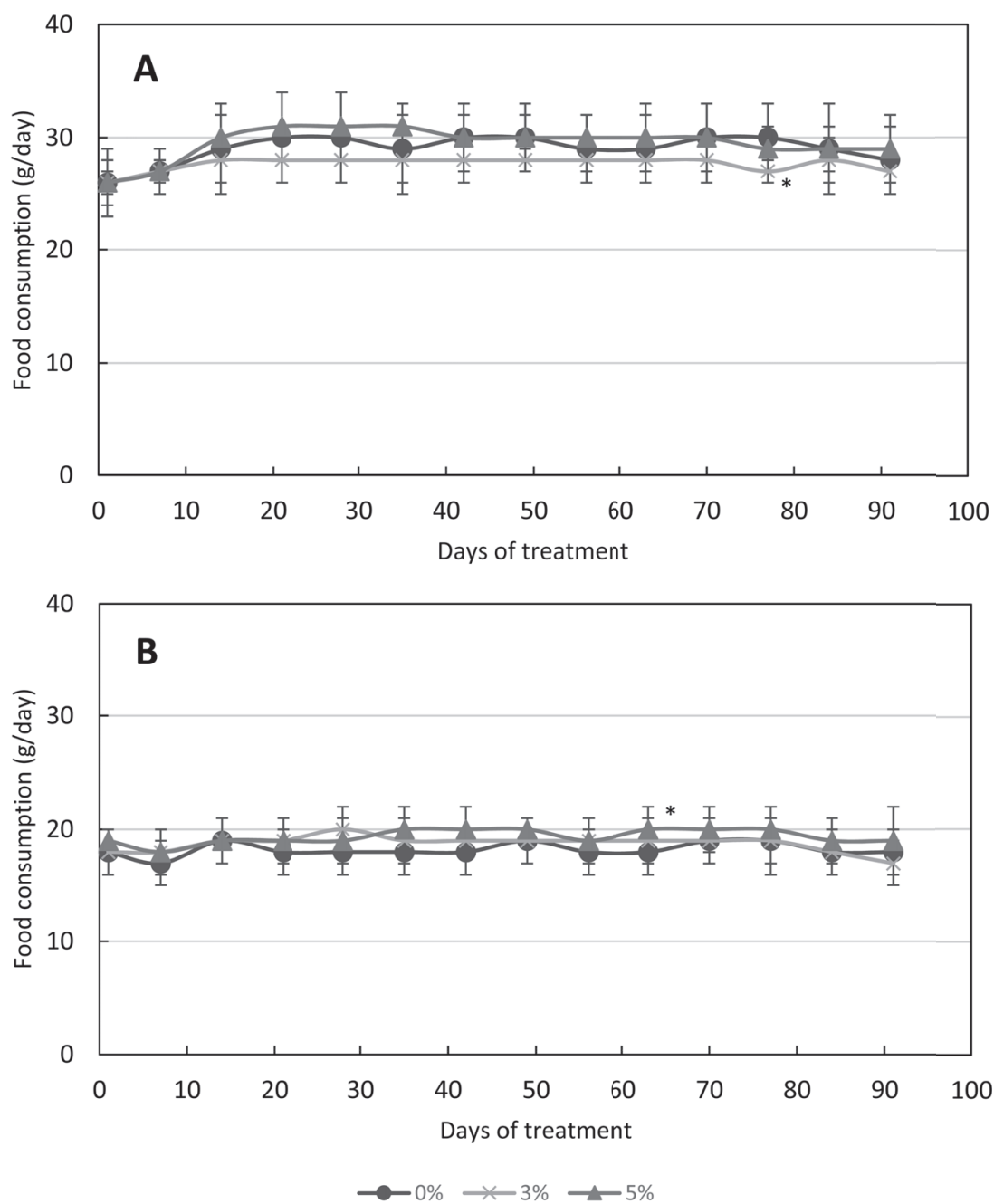

Fig. 1. Food consumption for male (A) and female (B) rats exposed for 90 days to RGM. Values are mean \pm S.D. *Significantly different from the control using Dunnett's test at $p<0.05$.

enced some gastrointestinal symptoms at the two higher dose levels ( 0.7 and $0.9 \mathrm{~g} / \mathrm{kg} \mathrm{BW})$. At a dose of $0.7 \mathrm{~g} / \mathrm{kg}$ $\mathrm{BW}$, four subjects reported gurgling sounds, two of these also reported flatus, and one of these two reported tenesmus and abdominal discomfort. At a dose of $0.9 \mathrm{~g} / \mathrm{kg}$ $\mathrm{BW}$, the same four subjects and two additional subjects reported gurgling sounds and flatus. Those who experienced gastrointestinal symptoms at $0.7 \mathrm{~g} / \mathrm{kg} \mathrm{BW}$ experienced the same symptoms at the higher dose level. All of these symptoms were mild and transient and improved spontaneously.

\section{DISCUSSION}

We performed a reverse mutation assay as part of our series of safety assessments of RGM, which confirmed that RGM was not mutagenic.

In their acute oral toxicity study of RGM in rats, Hamaguchi et al. (2015) reported that the LD50 value for RGM in male and female rats was more than $10,000 \mathrm{mg} / \mathrm{kg}$ BW per day. They did not look at repeated oral toxicity: therefore, we performed a 90-day subchronic oral toxicity study in rats to estimate the long-term safety of ingesting RGM.

One male rat in the $5 \% \mathrm{w} / \mathrm{w}$ group died on day 81 . This animal had shown no abnormalities in its gener- 
Safety assessment of resistant glucan mixture

Table 2. Urinalysis of 90-day oral toxicity study in rats ingesting a resistant glucan mixture.

\begin{tabular}{|c|c|c|c|c|c|c|c|}
\hline \multirow{2}{*}{$\begin{array}{l}\text { Sex } \\
\text { Dose }\end{array}$} & \multicolumn{4}{|c|}{ Male } & \multicolumn{3}{|c|}{ Female } \\
\hline & & $0 \%$ & $3 \%$ & $5 \%$ & $0 \%$ & $3 \%$ & $5 \%$ \\
\hline Number of animals & & 10 & 10 & 9 & 10 & 10 & 10 \\
\hline Urine volume (mL/day) & & $16 \pm 8.5$ & $11.1 \pm 3.2$ & $11.6 \pm 3.3$ & $11.3 \pm 8.8$ & $9.1 \pm 5$ & $7.8 \pm 4.3$ \\
\hline Water consumption (mL/day) & & $38 \pm 10$ & $36 \pm 5$ & $35 \pm 3$ & $41 \pm 22$ & $30 \pm 5$ & $31 \pm 8$ \\
\hline Osmotic pressure (mOsm/kg) & & $1866 \pm 412$ & $1878 \pm 347$ & $2069 \pm 328$ & $1740 \pm 648$ & $1728 \pm 401$ & $1923 \pm 614$ \\
\hline \multicolumn{8}{|c|}{ Electrolyte excretion (mmol/day) } \\
\hline $\mathrm{Na}$ & & $2.1 \pm 0.6$ & $1.6 \pm 0.3^{*}$ & $1.8 \pm 0.4$ & $1.2 \pm 0.4$ & $1.1 \pm 0.4$ & $1 \pm 0.3$ \\
\hline $\mathrm{K}$ & & $5.2 \pm 1.3$ & $3.9 \pm 0.6^{*}$ & $4.5 \pm 0.9$ & $2.9 \pm 1.1$ & $2.6 \pm 1$ & $2.4 \pm 0.6$ \\
\hline $\mathrm{Cl}$ & & $3.2 \pm 0.7$ & $2.4 \pm 0.4^{*}$ & $2.6 \pm 0.6$ & $1.8 \pm 0.6$ & $1.6 \pm 0.7$ & $1.4 \pm 0.5$ \\
\hline \multirow[t]{7}{*}{$\overline{\mathrm{pH}}$} & 6 & 0 & 1 & 0 & 1 & 0 & 1 \\
\hline & 6.5 & 0 & 0 & 1 & 1 & 1 & 2 \\
\hline & 7 & 1 & 1 & 0 & 1 & 1 & 3 \\
\hline & 7.5 & 0 & 0 & 1 & 1 & 1 & 0 \\
\hline & 8 & 1 & 1 & 0 & 0 & 1 & 1 \\
\hline & 8.5 & 6 & 4 & 4 & 2 & 3 & 2 \\
\hline & $\geqq 9$ & 2 & 3 & 3 & 4 & 3 & 1 \\
\hline \multirow[t]{4}{*}{ Protein } & - & 2 & 0 & 0 & 7 & 1 & 3 \\
\hline & \pm & 3 & 1 & 2 & 3 & 6 & 5 \\
\hline & $1+$ & 3 & 3 & 3 & 0 & 3 & 0 \\
\hline & $2+$ & 2 & 6 & 4 & 0 & 0 & 2 \\
\hline \multirow[t]{4}{*}{ Ketones } & - & 1 & 1 & 0 & 9 & 4 & 4 \\
\hline & \pm & 4 & 0 & 2 & 0 & 5 & 4 \\
\hline & $1+$ & 3 & 5 & 6 & 1 & 1 & 2 \\
\hline & $2+$ & 2 & 4 & 1 & 0 & 0 & 0 \\
\hline \multirow[t]{2}{*}{ Glucose } & - & 10 & 9 & 9 & 10 & 10 & 10 \\
\hline & + & 0 & 1 & 0 & 0 & 0 & 0 \\
\hline \multirow[t]{4}{*}{ Occult blood } & - & 9 & 8 & 6 & 10 & 10 & 10 \\
\hline & \pm & 1 & 1 & 3 & 0 & 0 & 0 \\
\hline & $1+$ & 0 & 0 & 0 & 0 & 0 & 0 \\
\hline & $2+$ & 0 & 1 & 0 & 0 & 0 & 0 \\
\hline Urobilinogen & \pm & 10 & 10 & 9 & 10 & 10 & 10 \\
\hline \multirow[t]{2}{*}{ Bilirubin } & - & 9 & 8 & 9 & 10 & 10 & 9 \\
\hline & + & 1 & 2 & 0 & 0 & 0 & 1 \\
\hline \multirow[t]{3}{*}{ Color } & LY & 0 & 0 & 0 & 0 & 0 & 0 \\
\hline & $\mathrm{Y}$ & 10 & 10 & 9 & 10 & 10 & 10 \\
\hline & DY & 0 & 0 & 0 & 0 & 0 & 0 \\
\hline $\mathrm{RBC}$ & - & 10 & 10 & 9 & 10 & 10 & 10 \\
\hline WBC & - & 10 & 10 & 9 & 10 & 10 & 10 \\
\hline SEC & \pm & 10 & 10 & 9 & 10 & 10 & 10 \\
\hline SREC & - & 10 & 10 & 9 & 10 & 10 & 10 \\
\hline Cast & - & 10 & 10 & 9 & 10 & 10 & 10 \\
\hline \multirow[t]{2}{*}{ Cr. PS } & - & 4 & 5 & 0 & 7 & 5 & 5 \\
\hline & \pm & 6 & 5 & 9 & 3 & 5 & 5 \\
\hline Cr. $\mathrm{CO}$ & - & 10 & 10 & 9 & 10 & 10 & 10 \\
\hline
\end{tabular}

Values are mean \pm S.D. *Significantly different from the control using Dunnett's test at $p<0.05$. Bilirubin:,- Negative;,$+ 0.8-1.6$ mg/dL. Cast: -, Negative. Color: LY, light yellow; Y, yellow; DY, dark yellow. Cr. CO (crystal calcium oxalate): -, Negative. Cr. PS (crystal phosphate salts): -, Negative; \pm , Slight. Glucose: -, Negative; +, 100-250 mg/dL. Ketones: -, Negative;, \pm 5-15; 1+, 15-40; $2+,>40$ mg/dL. Occult blood: -, Negative;, $\pm 0.015-0.062 ; 1+, 0.062-0.135 ; 2+, 0.135-0.405$ mg/dL. Protein: -, Negative;, $\pm 15-30 ;$ $1+, 30-100 ; 2+,>100 \mathrm{mg} / \mathrm{dL}$. RBC (red blood cells): -, Negative. SREC (small round epithelial cells): -, Negative. SEC (squamous epithelial cells): \pm , Slight. Urobilinogen:, $\pm 0.1-1 \mathrm{U} / \mathrm{dL}$. WBC (white blood cells): -, Negative. 
H. Bito et al.

Table 3. Hematological analysis of 90-day oral toxicity study in rats ingesting a resistant glucan mixture.

\begin{tabular}{|c|c|c|c|c|c|c|}
\hline \multirow{2}{*}{$\begin{array}{l}\text { Sex } \\
\text { Dose }\end{array}$} & \multicolumn{3}{|c|}{ Male } & \multicolumn{3}{|c|}{ Female } \\
\hline & $0 \%$ & $3 \%$ & $5 \%$ & $0 \%$ & $3 \%$ & $5 \%$ \\
\hline $\mathrm{RBC}\left(10^{4} / \mu \mathrm{L}\right)$ & $890 \pm 25$ & $893 \pm 43$ & $907 \pm 37$ & $829 \pm 24$ & $833 \pm 20$ & $816 \pm 25$ \\
\hline Hemoglobin $(\mathrm{g} / \mathrm{dL})$ & $16 \pm 0$ & $16 \pm 1$ & $16 \pm 1$ & $16 \pm 1$ & $15 \pm 0$ & $15 \pm 1$ \\
\hline Hematocrit (\%) & $46 \pm 1$ & $46 \pm 2$ & $46 \pm 2$ & $44 \pm 2$ & $44 \pm 1$ & $44 \pm 2$ \\
\hline MCV (fL) & $52 \pm 2$ & $51 \pm 2$ & $51 \pm 1$ & $53 \pm 2$ & $53 \pm 1$ & $54 \pm 1$ \\
\hline $\mathrm{MCH}(\mathrm{pg})$ & $17.8 \pm 0.5$ & $17.4 \pm 0.5$ & $17.2 \pm 0.5 *$ & $18.7 \pm 0.6$ & $18.5 \pm 0.5$ & $18.8 \pm 0.4$ \\
\hline $\operatorname{MCHC}(\mathrm{g} / \mathrm{dL})$ & $34 \pm 1$ & $34 \pm 1$ & $34 \pm 1$ & $35 \pm 0$ & $35 \pm 1$ & $35 \pm 1$ \\
\hline $\operatorname{Retic}\left(10^{9} / \mathrm{L}\right)$ & $190 \pm 19$ & $231 \pm 85$ & $216 \pm 40$ & $160 \pm 29$ & $153 \pm 25$ & $159 \pm 28$ \\
\hline $\operatorname{PLT}\left(10^{4} / \mu \mathrm{L}\right)$ & $98 \pm 9$ & $103 \pm 12$ & $103 \pm 13$ & $99 \pm 10$ & $109 \pm 12$ & $103 \pm 11$ \\
\hline $\mathrm{WBC}\left(10^{2} / \mu \mathrm{L}\right)$ & $68 \pm 21$ & $76 \pm 24$ & $75 \pm 11$ & $40 \pm 12$ & $47 \pm 10$ & $50 \pm 18$ \\
\hline $\operatorname{LYMP}\left(10^{2} / \mu \mathrm{L}\right)$ & $48 \pm 16$ & $52 \pm 13$ & $53 \pm 9$ & $30 \pm 10$ & $33 \pm 11$ & $38 \pm 15$ \\
\hline $\operatorname{NEUT}\left(10^{2} / \mu \mathrm{L}\right)$ & $17 \pm 7$ & $20 \pm 11$ & $18 \pm 6$ & $8 \pm 2$ & $12 \pm 4$ & $10 \pm 4$ \\
\hline $\operatorname{EOS}\left(10^{2} / \mu \mathrm{L}\right)$ & $1.1 \pm 0.3$ & $1.2 \pm 0.6$ & $1.2 \pm 0.4$ & $0.7 \pm 0.3$ & $0.8 \pm 0.2$ & $1.0 \pm 0.4$ \\
\hline $\operatorname{BASO}\left(10^{2} / \mu \mathrm{L}\right)$ & $0.2 \pm 0.1$ & $0.2 \pm 0.1$ & $0.2 \pm 0.1$ & $0.1 \pm 0.1$ & $0.1 \pm 0.0$ & $0.1 \pm 0.1$ \\
\hline MONO $\left(10^{2} / \mu \mathrm{L}\right)$ & $2.0 \pm 0.7$ & $2.2 \pm 1.0$ & $2.5 \pm 1.0$ & $0.7 \pm 0.4$ & $0.9 \pm 0.5$ & $1.1 \pm 0.7$ \\
\hline LUC $\left(10^{2} / \mu \mathrm{L}\right)$ & $0.5 \pm 0.4$ & $0.5 \pm 0.2$ & $0.7 \pm 0.3$ & $0.2 \pm 0.1$ & $0.3 \pm 0.1$ & $0.4 \pm 0.3$ \\
\hline PT (s) & $13 \pm 1$ & $14 \pm 1$ & $13 \pm 1$ & $12 \pm 1$ & $12 \pm 1$ & $12 \pm 1$ \\
\hline $\operatorname{APTT}(\mathrm{s})$ & $19 \pm 2$ & $18 \pm 3$ & $17 \pm 2$ & $13 \pm 1$ & $13 \pm 2$ & $14 \pm 2$ \\
\hline FIB (mg/dL) & $271 \pm 26$ & $247 \pm 29$ & $269 \pm 17$ & $211 \pm 28$ & $192 \pm 19$ & $185 \pm 15 *$ \\
\hline
\end{tabular}

Values are mean \pm S.D. *Significantly different from the control using Dunnett's test at $p<0.05$. APTT: activated partial thromboplastin time, BASO: basophils, EOS: eosinophils, FIB: fibrinogen volume, LUC: large unstained cells, LYMP: lymphocyte, MCH: mean corpuscular hemoglobin, MCHC: mean corpuscular hemoglobin concentration, MCV: mean corpuscular volume, MONO: monocyte, NEUT: neutrophils, PLT: platelet count, PT: prothrombin time, RBC: red blood cell count, Retic: reticulocyte count, WBC: white blood cell count.

al condition, body weight or food consumption before death. Although it showed macroscopic enlargement of the cecum and dilatation of the lumen in a histopathological examination carried out soon after death, no other abnormalities were observed. Dietary fiber is resistant to digestion and absorption in the small intestine so it reaches the large intestine where some dietary fibers are fermented by microbes. These microbes proliferate and hold water, contributing to the increasing amount of large intestinal contents. Yoshioka et al. (1994) reported that the ingestion of polydextrose was accompanied by a significant increase in cecal weight and contents in rats. Wakabayashi et al. (1991) reported that enlargement of the cecum was observed in rats fed a diet containing resistant maltodextrin. Because RGM is a water-soluble dietary fiber similar to polydextrose and resistant maltodextrin, it was suspected that RGM would be at least partly fermented by microbes, and proliferated microbes and holding water resulted in increasing the amount of cecal contents. It was considered that this change in the cecum would not be fatal to rats. Therefore, it was judged that the death in our study was incidental, and poorly related to the administration of RGM, because no observed abnormalities were associated with the death.

The body weights of rats across all groups that completed the test schedule were not significantly different. Food consumption compared with the control group was significantly higher at day 63 in the female $5 \% \mathrm{w} / \mathrm{w}$ group, and was significantly lower at day 77 in the male $3 \% \mathrm{w} / \mathrm{w}$ group. However, these significant differences were transient with no changes on the other days. The total food intake was not significantly different, thus RGM is not toxic with regard to the growth of rats. Urinalysis indicated that male rats in the $3 \% \mathrm{w} / \mathrm{w}$ group showed a significant decrease in urinary $\mathrm{Na}, \mathrm{P}$, and $\mathrm{Cl}$ compared with the control group. However, it was not a dose-related decrease because these urinary electrolytes in the 5\% w/w group did not show a significant difference. In addi- 
Safety assessment of resistant glucan mixture

Table 4. Blood chemical analysis of 90-day oral toxicity study in rats ingesting a resistant glucan mixture.

\begin{tabular}{|c|c|c|c|c|c|c|}
\hline Sex & & Male & & & Female & \\
\hline Dose & $0 \%$ & $3 \%$ & $5 \%$ & $0 \%$ & $3 \%$ & $5 \%$ \\
\hline $\mathrm{AST}(\mathrm{IU} / \mathrm{L})$ & $68 \pm 11$ & $58 \pm 6 *$ & $66 \pm 8$ & $55 \pm 9$ & $57 \pm 9$ & $66 \pm 35$ \\
\hline ALT (IU/L) & $29 \pm 3$ & $29 \pm 9$ & $31 \pm 7$ & $23 \pm 5$ & $22 \pm 3$ & $27 \pm 11$ \\
\hline LDH (IU/L) & $52 \pm 19$ & $44 \pm 12$ & $59 \pm 20$ & $34 \pm 8$ & $43 \pm 14$ & $48 \pm 27$ \\
\hline $\operatorname{ALP}(\mathrm{IU} / \mathrm{L})$ & $341 \pm 43$ & $290 \pm 53 *$ & $294 \pm 31 *$ & $180 \pm 53$ & $149 \pm 34$ & $149 \pm 31$ \\
\hline$\gamma$-GTP (IU/L) & $1 \pm 0$ & $1 \pm 0$ & $1 \pm 1$ & $1 \pm 1$ & $1 \pm 0$ & $1 \pm 1$ \\
\hline T-CHO (mg/dL) & $70 \pm 14$ & $63 \pm 13$ & $68 \pm 11$ & $73 \pm 21$ & $70 \pm 12$ & $75 \pm 18$ \\
\hline $\mathrm{TG}(\mathrm{mg} / \mathrm{dL})$ & $52 \pm 22$ & $62 \pm 41$ & $64 \pm 25$ & $17 \pm 8$ & $19 \pm 16$ & $19 \pm 8$ \\
\hline PL (mg/dL) & $109 \pm 17$ & $103 \pm 20$ & $106 \pm 15$ & $138 \pm 33$ & $135 \pm 25$ & $143 \pm 31$ \\
\hline T-BIL (mg/dL) & $0.1 \pm 0.0$ & $0.1 \pm 0.0$ & $0.1 \pm 0.0$ & $0.1 \pm 0.0$ & $0.1 \pm 0.0$ & $0.1 \pm 0.0$ \\
\hline GLU (mg/dL) & $146 \pm 11$ & $152 \pm 15$ & $148 \pm 14$ & $131 \pm 15$ & $133 \pm 19$ & $138 \pm 12$ \\
\hline BUN (mg/dL) & $14 \pm 1$ & $14 \pm 2$ & $15 \pm 2$ & $16 \pm 3$ & $16 \pm 2$ & $15 \pm 3$ \\
\hline CRE (mg/dL) & $0.25 \pm 0.04$ & $0.22 \pm 0.05$ & $0.24 \pm 0.05$ & $0.30 \pm 0.04$ & $0.28 \pm 0.02$ & $0.28 \pm 0.03$ \\
\hline $\mathrm{Na}(\mathrm{mmol} / \mathrm{L})$ & $145 \pm 1$ & $144 \pm 1$ & $145 \pm 1$ & $144 \pm 2$ & $143 \pm 1$ & $143 \pm 1$ \\
\hline $\mathrm{K}(\mathrm{mmol} / \mathrm{L})$ & $3.5 \pm 0.2$ & $3.5 \pm 0.2$ & $3.5 \pm 0.2$ & $3.3 \pm 0.3$ & $3.5 \pm 0.2$ & $3.4 \pm 0.3$ \\
\hline $\mathrm{Cl}(\mathrm{mmol} / \mathrm{L})$ & $108 \pm 2$ & $107 \pm 2$ & $107 \pm 2$ & $109 \pm 1$ & $109 \pm 1$ & $109 \pm 2$ \\
\hline $\mathrm{Ca}(\mathrm{mg} / \mathrm{dL})$ & $10.1 \pm 0.3$ & $10.1 \pm 0.3$ & $10.2 \pm 0.3$ & $10.1 \pm 0.3$ & $10.1 \pm 0.3$ & $10.2 \pm 0.4$ \\
\hline $\mathrm{P}(\mathrm{mg} / \mathrm{dL})$ & $5.3 \pm 0.9$ & $5.5 \pm 0.8$ & $5.4 \pm 0.8$ & $4.5 \pm 1.0$ & $4.7 \pm 1.4$ & $4.5 \pm 0.8$ \\
\hline $\mathrm{TP}(\mathrm{g} / \mathrm{dL})$ & $6.3 \pm 0.1$ & $6.2 \pm 0.2$ & $6.3 \pm 0.2$ & $6.8 \pm 0.3$ & $6.6 \pm 0.5$ & $6.7 \pm 0.4$ \\
\hline Albumin (\%) & $49 \pm 2$ & $50 \pm 2$ & $48 \pm 3$ & $57 \pm 2$ & $58 \pm 2$ & $59 \pm 2$ \\
\hline$\alpha-1$ Globulin (\%) & $18 \pm 2$ & $18 \pm 2$ & $19 \pm 3$ & $13 \pm 2$ & $12 \pm 2$ & $13 \pm 2$ \\
\hline$\alpha-2$ Globulin (\%) & $10 \pm 1$ & $9 \pm 2$ & $10 \pm 2$ & $9 \pm 1$ & $9 \pm 2$ & $8 \pm 1$ \\
\hline$\beta$ Globulin (\%) & $19 \pm 2$ & $19 \pm 2$ & $19 \pm 2$ & $16 \pm 2$ & $16 \pm 1$ & $15 \pm 1$ \\
\hline$\gamma$ Globulin (\%) & $5 \pm 2$ & $4 \pm 1$ & $5 \pm 2$ & $5 \pm 1$ & $6 \pm 2$ & $5 \pm 1$ \\
\hline $\mathrm{A} / \mathrm{G}$ ratio & $1.0 \pm 0.1$ & $1.0 \pm 0.1$ & $0.9 \pm 0.1$ & $1.3 \pm 0.1$ & $1.4 \pm 0.1$ & $1.4 \pm 0.1$ \\
\hline
\end{tabular}

Values are mean \pm S.D. *Significantly different from the control using Dunnett's test at $p<0.05$. A/G ratio: albumin /globulin ratio, ALP: alkaline phosphatase, ALT: alanine aminotransferase, AST: aspartate aminotransferase, BUN: blood urea nitrogen, Ca: calcium, Cl: chlorine, CRE: creatinine, GLU: glucose, $\gamma$-GTP: $\gamma$-glutamyl transpeptidase, LDH: lactate dehydrogenase, Na: sodium, K: potassium, P: inorganic phosphorus, PL: phospholipid, T-BIL: total bilirubin, T-CHO: total cholesterol, TG: triglyceride, TP: total protein.

tion, no abnormalities were found in BUN and CRE, the parameters of renal function or in the histopathological examination of the kidney. This suggested that the renal function was not disturbed. In some of the hematological and blood chemical examinations, we observed a significant difference between the control group and the RGM group. However, the values of those items remained within the normal range for rats at the facility Male rats in the $5 \% \mathrm{w} / \mathrm{w}$ group had significantly lower $\mathrm{MCH}$ than male rats in the control group, but in this group MCV and $\mathrm{MCHC}$ were not different, suggesting no anemia. Female rats in the $5 \% \mathrm{w} / \mathrm{w}$ group had significantly lower FIB than in the control group but because no change was observed in PT and APTT, we judged that RGM did not have a negative effect on styptic function and did not increase disseminated intravascular coagulation. A significantly low value in AST activity was recorded in the male $3 \% \mathrm{w} / \mathrm{w}$ group. However, this change was not dose-related. ALP in both male $3 \%$ and $5 \% \mathrm{w} / \mathrm{w}$ groups were significantly lower compared with the male control group. Although there was no significant difference, a decreasing trend for ALP in females was observed. Human serum ALP is generally composed of liver-, bone- and intestine-derived isoenzymes (Moss, 1992). In the case of rats, serum ALP 
H. Bito et al.

Table 5. Relative organ weight in 90-day oral toxicity study in rats ingesting a resistant glucan mixture.

\begin{tabular}{|c|c|c|c|c|}
\hline Dose & & $0 \%$ & $3 \%$ & $5 \%$ \\
\hline \multirow[t]{15}{*}{ Male } & Body weight (g) & $553 \pm 54$ & $524 \pm 36$ & $566 \pm 34$ \\
\hline & Brain $(g / 100 \mathrm{~g})$ & $0.40 \pm 0.03$ & $0.42 \pm 0.02$ & $0.39 \pm 0.03$ \\
\hline & Pituitary (mg/100 g) & $2.3 \pm 0.2$ & $2.4 \pm 0.2$ & $2.2 \pm 0.3$ \\
\hline & Thyroid gland $(\mathrm{mg} / 100 \mathrm{~g})$ & $4.6 \pm 0.7$ & $5.2 \pm 1.2$ & $4.2 \pm 1$ \\
\hline & Salivary gland $(\mathrm{mg} / 100 \mathrm{~g})$ & $144 \pm 13$ & $146 \pm 11$ & $143 \pm 14$ \\
\hline & Thymus (mg/100 g) & $53 \pm 11$ & $50 \pm 9$ & $48 \pm 7$ \\
\hline & Heart (g/100 g) & $0.28 \pm 0.02$ & $0.30 \pm 0.03$ & $0.27 \pm 0.01$ \\
\hline & Lung (g/100 g) & $0.29 \pm 0.02$ & $0.29 \pm 0.02$ & $0.28 \pm 0.02$ \\
\hline & Liver $(\mathrm{g} / 100 \mathrm{~g})$ & $2.4 \pm 0.3$ & $2.5 \pm 0.2$ & $2.5 \pm 0.2$ \\
\hline & Spleen $(g / 100 \mathrm{~g})$ & $0.14 \pm 0.02$ & $0.15 \pm 0.01$ & $0.14 \pm 0.02$ \\
\hline & Kidney (g/100 g) & $0.56 \pm 0.06$ & $0.61 \pm 0.05$ & $0.58 \pm 0.06$ \\
\hline & Adrenal gland $(\mathrm{mg} / 100 \mathrm{~g})$ & $11 \pm 2$ & $12 \pm 2$ & $11 \pm 2$ \\
\hline & Testis $(\mathrm{g} / 100 \mathrm{~g})$ & $0.64 \pm 0.06$ & $0.67 \pm 0.08$ & $0.62 \pm 0.07$ \\
\hline & Prostate (g/100 g) & $0.22 \pm 0.03$ & $0.26 \pm 0.03 *$ & $0.23 \pm 0.04$ \\
\hline & Seminal vesicle $(\mathrm{g} / 100 \mathrm{~g})$ & $0.26 \pm 0.05$ & $0.28 \pm 0.05$ & $0.25 \pm 0.04$ \\
\hline \multirow[t]{14}{*}{ Female } & Body weight, $g$ & $277 \pm 38$ & $278 \pm 31$ & $278 \pm 22$ \\
\hline & Brain $(g / 100 g)$ & $0.71 \pm 0.08$ & $0.73 \pm 0.1$ & $0.73 \pm 0.07$ \\
\hline & Pituitary (mg/100 g) & $5.1 \pm 0.8$ & $5.2 \pm 0.8$ & $5.1 \pm 0.5$ \\
\hline & Thyroid gland $(\mathrm{mg} / 100 \mathrm{~g})$ & $6.4 \pm 0.8$ & $6.2 \pm 0.5$ & $6.7 \pm 1.4$ \\
\hline & Salivary gland $(\mathrm{mg} / 100 \mathrm{~g})$ & $172 \pm 21$ & $170 \pm 15$ & $171 \pm 15$ \\
\hline & Thymus (mg/100 g) & $92 \pm 16$ & $92 \pm 18$ & $103 \pm 22$ \\
\hline & Heart (g/100 g) & $0.33 \pm 0.03$ & $0.33 \pm 0.04$ & $0.31 \pm 0.03$ \\
\hline & Lung (g/100 g) & $0.38 \pm 0.03$ & $0.40 \pm 0.03$ & $0.38 \pm 0.02$ \\
\hline & Liver (g/100 g) & $2.4 \pm 0.1$ & $2.3 \pm 0.1$ & $2.4 \pm 0.1$ \\
\hline & Spleen (g/100 g) & $0.16 \pm 0.01$ & $0.17 \pm 0.02$ & $0.16 \pm 0.01$ \\
\hline & Kidney (g/100 g) & $0.63 \pm 0.07$ & $0.62 \pm 0.06$ & $0.65 \pm 0.05$ \\
\hline & Adrenal gland $(\mathrm{mg} / 100 \mathrm{~g})$ & $22 \pm 4$ & $23 \pm 3$ & $21 \pm 2$ \\
\hline & Ovary (mg/100 g) & $30 \pm 7$ & $25 \pm 8$ & $27 \pm 6$ \\
\hline & Uterus (mg/100 g) & $198 \pm 33$ & $204 \pm 40$ & $202 \pm 27$ \\
\hline
\end{tabular}

Values are mean \pm S.D. *Significantly different from the control using Dunnett's test at $p<0.05$.

is derived mostly from bone and intestine. It is widely known that the amount of intestine-derived isoenzymes is high under satiation and low when fasting (Hatayama et al., 2012). Thus, the total ALP in rats is greatly affected by food intake. Failure to feed due to weakness or a decrease in food consumption due to the administration of a toxic drug dose can both lead to a reduction in ALP. In the present study, a decrease in ALP was observed through the ingestion of RGM, but no anomalies in body weight gain or decreases in food intake were observed. In addition, no changes in apparent toxicity were observed due to the ingestion of RGM from histopathological and other examinations, and there was no evidence of malnutrition. Although the reason its decrease was unknown, the ALP value was within the physiologically normal range, so we judged that RGM caused no toxic abnormalities. Regarding the organ weight and histopathological examinations, a few changes were observed in some organs and/or tissues. However, they were judged to be incidental because they can occur spontaneously in this strain of rat in this age group and there was no dose-related bias in their occurrence. The results of the 90-day subchronic oral tox- 
Safety assessment of resistant glucan mixture

Table 6. Stool characteristics in human subjects administered resistant glucan mixture.

\begin{tabular}{|c|c|c|c|c|c|}
\hline Dose (g/kg body weight) & & 0.3 & 0.5 & 0.7 & 0.9 \\
\hline All subjects $(N)$ & & 18 & 18 & 18 & 18 \\
\hline Defecating subjects $(\mathrm{N})$ & & 15 & 15 & 17 & 15 \\
\hline $\operatorname{Man}(\mathrm{N})$ & & 8 & 9 & 8 & 7 \\
\hline Woman $(\mathrm{N})$ & & 7 & 6 & 9 & 8 \\
\hline Non-defecating subjects $(\mathrm{N})$ & & 3 & 3 & 1 & 3 \\
\hline \multirow[t]{6}{*}{ Male } & Very hard (pellet-shaped) & 0 & 0 & 2 & 0 \\
\hline & Hard-solid & 0 & 0 & 0 & 0 \\
\hline & Normal (banana-shaped) & 6 & 5 & 2 & 4 \\
\hline & Soft, pasty & 2 & 4 & 4 & 3 \\
\hline & Muddy & 0 & 0 & 0 & 0 \\
\hline & Watery & 0 & 0 & 0 & 0 \\
\hline \multirow[t]{6}{*}{ Female } & Very hard (pellet-shaped) & 1 & 1 & 0 & 0 \\
\hline & Hard-solid & 0 & 1 & 0 & 0 \\
\hline & Normal (banana-shaped) & 5 & 2 & 7 & 4 \\
\hline & Soft, pasty & 1 & 2 & 2 & 4 \\
\hline & Muddy & 0 & 0 & 0 & 0 \\
\hline & Watery & 0 & 0 & 0 & 0 \\
\hline \multirow[t]{6}{*}{ Total } & Very hard (pellet-shaped) & 1 & 1 & 2 & 0 \\
\hline & Hard-solid & 0 & 1 & 0 & 0 \\
\hline & Normal (banana-shaped) & 11 & 7 & 9 & 8 \\
\hline & Soft, pasty & 3 & 6 & 6 & 7 \\
\hline & Muddy & 0 & 0 & 0 & 0 \\
\hline & Watery & 0 & 0 & 0 & 0 \\
\hline
\end{tabular}

The study of maximum no-effect dose for diarrhea in humans was carried out in 20 subjects (10 men and 10 women). Two subjects ( 1 man and 1 woman) abandoned the study for reasons unconnected with the test substance, the remaining subjects (9 men and 9 women) completed the schedule.

icity study in rats indicated that the No-Observed Adverse Effect Level (NOAEL) of RGM was $3.3 \mathrm{~g} / \mathrm{kg} \mathrm{BW}$ per day for males and $3.9 \mathrm{~g} / \mathrm{kg} \mathrm{BW}$ per day for females.

For human subjects in the present study, the maximum no-effect dose for diarrhea of RGM was more than $0.9 \mathrm{~g} / \mathrm{kg}$ BW for both sexes. As a comparison, the maximum noeffect doses for diarrhea for other indigestible carbohydrates are: resistant maltodextrin, $1.0 \mathrm{~g} / \mathrm{kg} \mathrm{BW}$ for men and more than $1.1 \mathrm{~g} / \mathrm{kg} \mathrm{BW}$ for women (Kishimoto et al., 2013); polydextrose, $0.7 \mathrm{~g} / \mathrm{kg} \mathrm{BW}$ (Flood et al., 2004); fructooligosaccharide, $0.3 \mathrm{~g} / \mathrm{kg} \mathrm{BW}$ for men and $0.4 \mathrm{~g} / \mathrm{kg}$ BW for women (Hata and Nakajima, 1985); and maltitol, $0.3 \mathrm{~g} / \mathrm{kg} \mathrm{BW}$ (Niwa et al., 1981). Carbohydrates such as dietary fiber, oligosaccharides and sugar alcohols are not (or are rarely) digested in the small intestine, so reach the large intestine. This increases the osmotic pres- sure in the large intestinal lumen, which is involved in diarrhea. Because the osmotic pressure is greatly affected by the molar concentration of substances, it increases as the molecular weight (MW) of the substance decreases, assuming the weight concentration remains the same. On the basis of MW, it would be reasonable to assume that resistant maltodextrin $(2,000 \mathrm{Da})$ and polydextrose $(2,000 \mathrm{Da})$ would have higher no-effect levels for diarrhea than fructooligosaccharide $(520 \mathrm{Da})$ and maltitol (344 Da). The average MW of RGM is $1900 \mathrm{Da}$, closer to that of resistant maltodextrin and polydextrose than fructooligosaccharide and maltitol. Therefore, the maximum no-effect dose of RGM was also similar to those of resistant maltodextrin and polydextrose. However, these carbohydrates are at least partly fermented by microbes, and the fermentation product is also involved in increas- 
ing osmotic pressure in the lumen. Acute diarrhea is affected not only by the MW of a substance but also by its fermentation pattern, because SCFA (acetate, propionate, butyrate) have a higher rate of absorption in the large intestine compared with lactate and succinate (Hoshi et al., 1994). Osmotic pressure in the large intestine is also influenced by the flow of indigestible material into the large intestine depending on the digestion and absorption rate of the materials. The fermentation pattern and digestibility rate of RGM are not yet completely understood so this is a subject for future investigation.

In conclusion, the present results have indicated that RGM shows no mutagenicity; the 90-day subchronic oral toxicity study in rats showed no abnormalities related to RGM with NOAEL values of $3.3 \mathrm{~g} / \mathrm{kg}$ BW per day for males and $3.9 \mathrm{~g} / \mathrm{kg} \mathrm{BW}$ per day for females. The maximum no-effect dose for diarrhea in humans was more than $0.9 \mathrm{~g} / \mathrm{kg} \mathrm{BW}$ for men and women.

Conflict of interest---- The authors declare that there is no conflict of interest.

\section{REFERENCES}

Choi, Y.S., Cho, S.H., Kim, H.J. and Lee, H.J. (1998): Effects of soluble dietary fibers on lipid metabolism and activities of intestinal disaccharidases in rats. J. Nutr. Sci. Vitaminol., 44, 591600.

Flood, M.T., Auerbach, M.H. and Craig, S.A.S. (2004): A review of the clinical toleration studies of polydextrose in food. Food Chem. Toxicol., 42, 1531-1542.

Hamaguchi, N., Hirai, H., Aizawa, K. and Takada, M. (2015): Production of water-soluble indigestible polysaccharides using activated carbon. J. Appl. Glycosci., 62, 7-13.

Hammer, H.F., Fine, K.D., Santa Ana, C.A., Porter, J.L., Schiller, L.R. and Fordtran, J.S. (1990): Carbohydrate malabsorption. Its measurement and its contribution to diarrhea. J. Clin. Invest., 86, 1936-1944.

Hata, Y. and Nakajima, K. (1985): Furakutoorigotou sessyu to ityoushoujou no kankei. (Japanese), Geriat. Med., 23, 817-828.

Hatayama, K., Ichikawa, Y., Nishihara, Y., Goto, K., Nakamura, D., Wakita, A. and Kobayashi, J. (2012): Serum alkaline phosphatase isoenzymes in SD rats detected by polyacrylamide-gel disk electrophoresis. Toxicol. Mech. Method, 22, 289-295.

Hoshi, S., Sakata, T., Mikuni, K., Hashimoto, H. and Kimura, S. (1994): Galactosylsucrose and xylosylfructoside alter digestive tract size and concentrations of cecal organic acids in rats fed diets containing cholesterol and cholic acid. J. Nutr., 124, 52-60.

JECFA (1981): Polydextroses modified. In: Toxicological Evaluation of Certain Food Additives, pp.144-168, WHO Food Additive Series, No. 16.

Jie, Z., Bang-Yao, L., Ming-Jie, X., Hai-Wei, L., Zu-Kang, Z., Ting-Song, W. and Craig, S.A. (2000): Studies on the effects of polydextrose intake on physiologic functions in Chinese people. Am. J. Clini. Nutr., 72, 1503-1509.
Kametani, N., Asakura, R., Mitsuda, H., Shioya, N. and Komori, Y. (2009): Effects of mixing tea beverage containing resistant maltodextrin on postprandial serum triglyceride and safety evaluation of long-term or excessive intake of the beverage. Jpn. J. Food Chem. Safety, 16, 20-27.

Kishimoto, Y., Oga, H., Tagami, H., Okuma, K. and Gordon, D.T. (2007): Suppressive effect of resistant maltodextrin on postprandial blood triacylglycerol elevation. Eur. J. Nutr., 46, 133-138.

Kishimoto, Y., Kanahori, S., Sakano, K. and Ebihara, S. (2013): The maximum single dose of resistant maltodextrin that does not cause diarrhea in humans. J. Nutr. Sci. Vitaminol., 59, 352-357.

Kobayashi, T., Otsuka, S. and Yugari, Y. (1979): Effect of chitosan on serum and liver cholesterol levels in cholesterol-fed rats. Nutr. Rep. Int., 19, 327-334.

Mascolo, N., Rajendran, V.M. and Binder, H.J. (1991): Mechanism of short-chain fatty acid uptake by apical membrane vesicles of rat distal colon. Gastroenterology, 101, 331-338.

Moss, D.W. (1992): Perspectives in alkaline phosphatase research. Clin. Chem., 38, 2486-2492.

Niwa, H., Hikichi, N., Sakurai, E., Ueda, M. and Fukuse, G. (1981): Alteration of biogenic amines, serotonin, histamine and polyamines, in cases of diarrhea induced by sugar alcohols. J. Pharm. Soc. Jpn., 101, 567-574.

OECD (1997): No. 471. Bacterial reverse mutation test. OECD guideline for testing of chemicals.

Okuma, K., Matsuda, I., Katta, Y. and Hanno, Y. (1990): Pyrolysis of starch and its digestibility by enzymes characterization of indigestible dextrins. Denpun Kagaku, 37, 107-114.

Okuma, K. and Matsuda, I. (2002): Indigestible fractions of starch hydrolysates and their determination method. J. Appl. Glycosci., 49, 479-485.

Peuranen, S., Tiihonen, K., Apajalahti, J., Kettunen, A., Saarinen, M. and Rautonen, N. (2004): Combination of polydextrose and lactitol affects microbial ecosystem and immune responses in rat gastrointestinal tract. Br. J. Nutr., 91, 905-914.

Pronczuk, A. and Hayes, K.C. (2006): Hypocholesterolemic effect of dietary polydextrose in gerbils and humans. Nutr. Res., 26, 27-31.

Shimomura, Y., Maeda, K., Nagasaki, M., Matsuo, Y., Murakami, T., Bajotto, G., Sato, J., Seino, T., Kamiwaki, T. and Suzuki, M. (2005): Attenuated response of the serum triglyceride concentration to ingestion of a chocolate containing polydextrose and lactitol in place of sugar. Biosci. Biotechnol. Biochem., 69, 18191823.

Sugano, M., Fujikawa, T., Hiratsuji, Y. and Hasegawa, Y. (1978): Hypocholesterolemic effects of chitosan in cholesterol-fed rats. Nutr. Rep. Int., 18, 531-537.

Trowell, H., Southgate, D.A., Wolever, T.M., Leeds, A.R., Gassull, M.A. and Jenkins, D.J. (1976): Dietary fibre redefined. Lancet, $1,967$.

Wakabayashi, S., Satouchi, M., Nogami, Y., Ohkuma, K. and Matsuoka, A. (1991): Effect of indigestible dextrin on cholesterol metabolism in rat. J. Jpn. Soc. Nutr. Food Sci., 44, 471-478.

Wakabayashi, S., Kishimoto, Y., Nanbu, S. and Matsuoka, A. (1999): Effects of indigestible dextrin on postprandial rise in blood glucose levels in man. J. Jpn. Assoc. Dietary Fiber Res., 3, 13-19.

Yoshioka, M., Shimomura, Y. and Suzuki, M. (1994): Dietary polydextrose affects the large intestine in rats. J. Nutr., 124, 539-547. 